\title{
Hayek: da teoria do mercado como ordem espontânea ao mercado como fim da história
}

Angela Ganem'

\section{Resumo}

O texto tem como objetivo demonstrar a centralidade do conceito de ordem espontânea do mercado em Hayek, examinando-a sob múltiplos aspectos, que vão desde conceito estruturante de seu edifício teórico à ideia de que a ordem social dele derivada é concebida como a melhor forma de organização social para as sociedades contemporâneas. O paper tem como objetivo subjacente sublinhar a atualidade da obra de Hayek, este que foi uma das maiores expressões do ultraliberalismo, destacando a sua perspectiva de cosmovisão da sociedade, a sua crítica filosófica ao racional construtivismo, bem como a sua concepção de um indivíduo ignorante frente à complexidade do mundo. O segundo movimento do trabalho trata das contradições da teoria da evolução cultural hayekiana em que o mercado é compreendido como passado, presente e futuro das sociedades. Este último ponto em que o mercado é compreendido como fim da história nos permite identificar a perspectiva ultrarracionalista de Hayek e apontar como a sua teoria alimenta uma apologética defesa do mercado como a única forma de organização para as sociedades contemporâneas.

Palavras-chave: Hayek. Ordem espontânea. Evolução cultural. Fim da história.

\section{A construção do conceito na trajetória intelectual: teoria e política}

Friedrich August Von Hayek nasceu em 1899, em Viena, e faleceu em 1993, em Fribourg, na Alemanha. Sua vida atravessou o século XX, um século rico em debates polarizados, em confrontos teóricos, políticos e ideológicos, reflexo, entre muitas outras ocorrências, das guerras, da instigante e

I Doutora em Sciences Économiques pela Universidade de Paris X, França, Professora Visitante do Instituto de Economia da Universidade Federal do Rio de Janeiro (UFRJ) - Brasil. E-mail: aganem@terra.com.br. Agradeço aos pareceristas da Revista Política e Sociedade pelas pertinentes sugestões. 
problemática experiência do socialismo real e do horror irracional do Holocausto. Do ponto de vista filosófico, severas críticas às limitaçóes e à incompletude do projeto iluminista partiam das mais variadas vertentes. Hayek fará a sua crítica a partir de uma perspectiva ultraliberal. Este autor, que foi uma das maiores expressóes teórico-ideológicas do neoliberalismo, manteve durante toda a sua vida um compromisso intelectual e político: a crítica ao socialismo como projeto social e a construçáo teórica central do mercado como uma ordem espontânea, viável e melhor forma de organização social para as sociedades contemporâneas.

Hayek pertencia a uma família de intelectuais de Viena, cidade considerada um dos mais brilhantes centros artísticos e intelectuais da Europa. Do ponto de vista político, Hayek cresceu presenciando a estruturação do partido social democrata criado em 1889, os avanços do populismo e do socialismo marxista. Entre 1919 e 1934, Viena esteve dirigida por socialistas, palco de uma administraçáo voltada para programas sociais e apoiada por movimentos operários. Arroubos ou não de juventude, o jovem Hayek àquela altura já fazia críticas contundentes às autoridades municipais e expressava, ainda que de forma incipiente, seu antissocialismo, "sua aversáo aos movimentos populares e suas críticas à justiça social [...]”. (DOLSTATER, 2001)

Nosso autor foi primo de Wittgenstein e primeiro leitor do Tractatus lógico-philosophicus, o livro que influenciou o nascimento do Círculo de Viena, berço do positivismo lógico. Embora aluno de Ernst Mach, fundador do Círculo, Hayek contestava os fundamentos da instituição. Ele se contrapunha, sobretudo, à defesa feita pela instituição da unidade metodológica para a ciência e dos critérios de cientificidade ditados pela física, o que o levou a estudar várias áreas do saber social superando fronteiras disciplinares. Embora inicialmente tenha se dedicado às ciências da natureza, assim que se inscreveu na Universidade de Viena seguiu disciplinas de vários cursos, na intuição de que não poderia se limitar a um único campo do conhecimento. Essa preocupaçáo com uma perspectiva interdisciplinar foi a marca do seu trabalho, fornecendo-lhe uma qualidade que poucos intelectuais dispóem - a capacidade de articular várias esferas do saber numa complexa cosmovisão da sociedade. Essa perspectiva abstrata e geral do seu trabalho fez com que a sua teoria do mercado como uma ordem espontânea se situasse para além do campo econômico ou de qualquer disciplina stricto sensu e residisse no plano ambicioso de uma teoria da sociedade: o mercado como ordem social. 
Em 1921 doutorou-se em Direito, ao mesmo tempo que frequentava os seminários privados de Ludwig Von Mises, eminente autor da escola austríaca de economia. Mises, que se contrapunha ao positivismo lógico, construiu uma metodologia apoiada na ação humana individual. Segundo historiadores do pensamento e biógrafos do nosso autor, foi Mises quem levou Hayek, de uma forma mais consistente, para o campo liberal radical em oposição frontal ao socialismo (BUTLER, 1987; DOSTALER, 2001; DOSTALER e ETHIER, 1980).

Dois anos depois, em 1923, doutorou-se em ciência política. Também neste ano passa a residir nos EUA, onde fica por 15 meses como estudante pesquisador. Ele inicia seu doutorado em Economia na Universidade de Nova Iorque e frequenta seminários em Yale. Embora náo tenha concluído o doutorado, foi nos EUA que Hayek sentiu a necessidade de ligar a teoria monetária a uma explicação das flutuaçóes cíclicas do capitalismo, assunto que lhe rendeu inúmeros artigos e três livros, inaugurando através de um grande debate do século sua trajetória intelectual.

Em 1924 ele retorna a Viena e, em 1927, é nomeado diretor do Instituto Austríaco de Pesquisa em Economia, especializado em estudos de ciclos econômicos. Hayek, por essa época, profere inúmeras conferências sobre economia na Universidade de Viena. Em 1931, Lionel Robbins, entusiasmado com sua capacidade e eloquência, o convida a fazer conferências na London School of Economics com um objetivo claro: combater Keynes. Nesse momento, Keynes era o diretor do Economic Journal e a maior expressão na Inglaterra da defesa do intervencionismo. Embora tenha mantido uma relação polida com Hayek, no mais das vezes Keynes reagiu violentamente às suas críticas.

Em Londres, Hayek viverá de 1931 a 1949. As primeiras conferências que ministrou nesse período foram reunidas no livro Prices and Production, publicado em 1931, no qual Hayek faz uma reflexáo sobre a crise de 1929 e defende, entre outros argumentos, a ideia de que a estrutura produtiva é flexível e depende unicamente das expectativas de lucros dos investidores. Além de vários artigos publicados neste período, Hayek publica o livro Monetary Theory and the Trade Cycles, em alemão em 1929, e em inglês, em 1931. Em 1937, Hayek publica Economics and Knowledge, em que critica a teoria do equilíbrio geral neoclássica, afirmando que o modelo é uma tautologia formal e que os preços são mecanismos de transmissáo de informaçóes, e não soluçóes 
para modelos. Em 1941, publica The Pure Theory of Capital, sua última obra teórica em economia, no qual analisa a natureza do capital. Embora seus livros tenham tido um relativo sucesso, eles terminaram por ser eclipsados pela força da teoria econômica keynesiana e pelo sucesso das políticas dela derivadas no enfrentamento à crise de 1929.

Hayek ainda escreverá alguns artigos em economia, mas é facilmente perceptível pela análise da trajetória da sua obra uma mudança de enfoque. Ele parece vislumbrar duas questóes importantes que orientarão sua trajetória intelectual: a necessidade de fundamentar pelo individualismo metodológico uma teoria do mercado liberal que abrangesse vários aspectos da sociedade $\mathrm{e}$ uma crítica mais consistente ao planejamento socialista. Nesse intento, ele publicará dois livros que marcam este movimento teórico e político: The Road to Serfdom em 1944, e Individualism and Economic Order, em 1948.

Em Individualism, Hayek critica a eficiência do cálculo socialista no planejamento econômico e escreve ensaios sobre a natureza da filosofia individualista e sobre a especificidade das ciências sociais. Trata-se de um livro na esfera da epistemologia, da filosofia da ciência e da metodologia. Já o Caminho da servidão, publicado originalmente em 1944, tinha uma ambição político-ideológica clara: a pretensão de derrubar a visão profética do socialismo decorrente das leis marxistas da história e, assim, construir um projeto ideológico de reabilitação do liberalismo.

A ação prática coerente com essa proposta é atestada pelo fato de ele ter sido o principal articulador do colóquio que criou a Sociedade de Mont Pelérin, organizaçáo que presidiu por 14 anos. Hayek foi o mentor desse encontro que ocorreu na Suíça em 1947, onde estavam presentes, entre os trinta e sete ilustres participantes, Karl Popper, Lionel Robbins, Milton Friedman, Machlup, Franz Knigth, Von Mises, Michael Polanyi e Maurice Allais. A preocupaçáo de Hayek era reunir nomes da Europa e dos EUA para formar uma frente de reabilitaçáo intelectual do liberalismo que tinha como objetivo fundamental "descobrir meios para enfrentar a crise moral, intelectual e econômica da Europa do pós-guerra, construindo um projeto político-econômico para um povo livre numa grande sociedade". Como subproduto desse projeto, a instituição defendia a ideia de denunciar os inimigos da sociedade aberta $\mathrm{e}$ determinar as causas da crise europeia através de uma crítica contundente ao fascismo e ao stalinismo. 
Os inimigos dessa sociedade aberta eram os regimes totalitários do fascismo e do stalinismo. Entretanto, a crítica de Hayek, como a de Popper², concentrou-se no stalinismo, pois o objetivo ideológico de ambos era atingir a construção de uma nova forma de organização da sociedade que não fosse a regida pelo mercado capitalista. Para Hayek, o melhor exemplo do caminho da servidão é o caminho traçado pelo plano ou desígnio de uma classe operária, uma razão onipotente que entende a sociedade como uma máquina racional ou uma ordem fabricada. Embora crítico ao totalitarismo nas duas grandes expressóes em que este se apresentou na história do século XX, Hayek concentrou-se no "caminho da servidão" instaurado pelo que considerou o racional construtivismo de Marx, ou os dissabores do totalitarismo de uma ordem que é fruto do plano ou do desígnio de uma classe operária consciente. Hayek constrói sua crítica a Marx concentrando-se naquilo que seria o pecado capital da razão: uma razáo onipotente oriunda da classe operária que transformaria a sociedade numa máquina racional, ou uma razão que é capaz de digerir a sua própria complexidade e que constrói pela deliberação de seus sujeitos sociais um devir socialista. (GANEM, 2009) ${ }^{3}$.

Em 1950 Hayek aceita o convite para ser professor na Universidade de Chicago. Será nos EUA que ele irá encontrar um clima mais profícuo do que na Europa do pós-guerra para as suas ideias ultraliberais. Lá, ele aprofunda questóes de ordem epistemológica publicadas no livro The Counter revolution of science, uma crítica fundamentada na aplicação dos métodos científicos das ciências físicas às ciências sociais; e The Sensory Order, obra que reúne suas reflexôes da década de 1920. Ambos os livros serão publicados em 1952 pela Universidade de Chicago.

2 Karl Popper escreve nessa mesma época uma crítica ao marxismo. Ambos foram duros com a ideia de um fim da história associado ao que chamaram de profético mundo socialista. Guardadas as diferenças de método, a Miséria do historicismo de 1944 e A sociedade aberta e seus inimigos de 1945, ambos de Popper, e o Caminho da servidão, de Hayek, publicado originalmente em 1944, têm o mesmo alvo: desmontar cientificamente o argumento da possibilidade de uma leitura da história e derrubar a visão profética do socialismo decorrente de supostas leis imanentes. (GANEM, 2009a).

3 Sua crítica ao marxismo é da mesma natureza que a de Popper. Trata-se de uma crítica frágil que ignora o tratamento dialético-materialista de Marx, em que, a partir de uma perspectiva de totalidade, torna compreensivel o agir dos sujeitos na história. Além disso, a sua leitura economicista e positivista do marxismo está informada pelos desvios stalinistas do projeto socialista. As inúmeras críticas que partiram do interior da tradição marxista são absolutamente ignoradas pelo autor. 
Entretanto, é no livro The Constitution of Liberty (1960) que se é possível observar a primeira etapa de elaboração de uma teoria liberal sistemática. Em The Constitution, Hayek explora a complexidade da sociedade, os fundamentos da liberdade individual e o estado de direito necessário a uma sociedade livre, temas centrais da sua trajetória intelectual.

Por essa época Hayek escreve Studies in Philosophy, Politics and Economics, que é publicado em 1967. Nesse livro, ele desenvolve os conceitos que tomarão um sentido completo e acabado em Law, Legislation and Liberty, apresentado em três tomos, o primeiro publicado em 1973, e os outros em 1976 e 1979, respectivamente.

Direito, legislação e liberdade é uma obra central para a compreensão do edifício teórico de Hayek. Ela reúne de forma articulada as pré-condiçóes pelo direito da ordem espontânea do mercado, seu conceito central e sua maior contribuição teórica. Uma ordem que emerge espontaneamente, sem plano, desígnio ou Estado. Partindo de uma crítica filosófica ao racionalismo construtivista, Hayek trabalha sob vários prismas o seu ponto de partida metodológico: o indivíduo, um homem ignorante e livre frente a um mundo complexo, que num processo de experimentação, entre erros e acertos, elege as regras que representam a possibilidade da emergência da ordem na great society.

À época em que escreve esse livro seminal (década de 1960), Hayek vive na Alemanha e depois na Áustria. Em 1962 ele ingressa na Universidade de Fribourg, na Alemanha, onde se torna professor honorário. Em 1967 ele aceita o cargo de professor honorário na Universidade de Salsbourg, na Áustria. Nessa época, com a saúde debilitada, Hayek recebe muitas honrarias, como a de doutor honorário em Tóquio, a de senador honorário em Viena e, a mais importante, em 1974, quando recebe o prêmio Nobel (dividido com Gunnar Myrdall) pelo conjunto de sua obra.

Em 1977 ele retorna à Universidade de Fribourg e tenta organizar em Paris um encontro internacional entre liberais e socialistas, mas não obtém êxito. O texto preparatório do encontro é o ponto de partida para o livro publicado em 1988: The Fatal Conceit: the errors of socialism. Em 1978 publica pela Universidade de Chicago New Studies in Philosophy, Politics, Economics and the History of Ideas. Em 1992, Hayek, aos 93 anos, falece em Fribourg ainda coerente com as ideias que o perseguiram até os últimos anos de sua vida: a crítica ao socialismo aliada à ambição de construir a partir de uma abordagem 
interdisciplinar os fundamentos do mercado como uma ordem social espontânea. Em que pese alguns problemas e contradiçóes teóricas (que veremos a seguir), Hayek foi um dos mais importantes autores da perspectiva ultraliberal da atualidade alimentando decisivamente a apologia da defesa do mercado como a melhor forma de organização para as sociedades contemporâneas.

Em 1991, é publicado o primeiro dos 19 volumes previstos do The Collected Works of F.A. Hayek, pela Routledge, Taylor \& Francis Group Editora que segue publicando sua vasta obra.

\section{A estrutura teórica de Hayek}

A maior contribuição teórica de Hayek é a sua teoria da ordem espontânea do mercado entendida como uma teoria da sociedade, isto é, o mercado como inteligibilidade da ordem social. Sua teoria do mercado suscita o enfrentamento de múltiplos desafios: em primeiro lugar porque se trata de uma teoria assentada numa cosmovisão da sociedade, em que vários saberes se articulam. Em segundo lugar porque fornece contribuiçóes metodológicas atuais, estabelecendo através das regras e das instituiçóes um fino diálogo com a heterodoxia. Em terceiro lugar porque se constitui numa apurada crítica à formulação matemática do mercado autorregulado da teoria neoclássica, apresentando-se como uma alternativa mais sedutora do que os pesados modelos matemáticos da ortodoxia. Finalmente, e não menos importante, sua teoria traz articulada a si uma ambição política e ideológica neoliberal: a de fornecer uma estrutura teórica considerada como a melhor forma de organização social para as sociedades contemporâneas que substituirá a utopia socialista pelo mercado como fim da história.

\section{I A ordem social do mercado num breve retrospecto histórico}

Hayek constrói sua teoria do mercado como ordem espontânea, retomando Smith e criticando a ordem racional walrasiana. É possível tecer uma linha entre esses três autores tendo a concepção do mercado como ordem social como fio condutor. Para nós, ela aparece originariamente na história do pensamento econômico e na história das ideias através da solução de Adam Smith frente aos filósofos do contrato, avança analiticamente um século depois na tentativa de demonstraçáo lógico-matemática da Teoria do Equilíbrio Geral em Walras para adquirir a souplesse teórica necessária à sobrevivência do 
neoliberalismo no século XX na teoria de Hayek, em que a história realizaria o autodesenvolvimento da ordem do mercado. (GANEM, 2010b)

No que diz respeito à história da implantação do capitalismo, a ordem natural do mercado de Adam Smith é o resultado de uma leitura testemunhal, descritiva e empírica desse fenômeno. A essa perspectiva, alie-se a capacidade incontestável do autor de construir leis naturais que fornecem as condiçóes epistemológicas necessárias para o nascimento da economia marcado pela ideia do mercado como ordem social. O segundo momento, expresso na ordem racional de Walras, situa-se na segunda metade do século XIX, momento este em que se constata o apogeu do laissez-faire como teoria e política do capitalismo e do mercado. Nesse período, tem-se a afirmação da economia positiva cientificamente espelhada na física. Finalmente, o terceiro momento, no final do século XX, após a crise do comunismo e do welfare state, tem em Hayek uma teoria que alimenta as possibilidades de se articular o fim da história com a vitória da globalização e da democracia liberal sob a égide da supremacia do mercado.

É interessante como Adam Smith, Leon Walras e F. A. Hayek, distribuídos no tempo e no espaço da História do Pensamento Econômico, têm como elo teórico o mercado autorregulável para a explicação da ordem social capitalista. A distância que separa cada um de seu sucessor é de um século, e nos três é possível identificar a compreensão do objeto mercado para além dos limites do mecanismo de oferta e demanda, situando-o no plano de uma ordem social, ou de uma teoria da sociedade, ou ainda na forma de organização da sociedade capitalista. A singularidade e a genialidade desses autores se constatam nas marcas indeléveis que deixaram na história das ideias, na história do pensamento econômico e na influência nas políticas econômico-sociais implementadas pelos países capitalistas.

Em Smith, a economia nasce como uma teoria do mercado, uma explicação científica para a emergência da ordem liberal. Smith apresenta a fórmula ou a lógica do mercado liberal em seu estado mais puro, espontâneo e natural, em que os interesses privados ao invés de se chocarem produzindo a guerra são agraciados por uma mão invisível que os orienta para o bem-estar coletivo. Essa solução de Smith alçou a economia ao debate das ideias da modernidade como também definiu um dos projetos teóricos da disciplina, inserindo-o dentro do projeto liberal. Nesta explicação, Adam Smith construiu um 
profundo diálogo com os modernos e definiu os fundamentos da economia imbricados com a filosofia moral dos séculos XVII e XVIII. A solução do mercado de Smith para a ordem social supera a noção do contrato como lógica para os fenômenos coletivos. Sua explicação do mercado náo se limita a um estudo do "local de trocas" e a economia termina por invadir todo o terreno da sociedade. Essa ordem social explicada a partir do indivíduo - o homem como ele realmente é - com as suas paixóes, sem intencionalidades e/ou desígnios, gera dentro dessa perspectiva o bem-estar coletivo.

Já o segundo momento, datado de fins do século XIX, está inserido no quadro da revolução marginalista e de uma mudança de paradigma na economia, que tem em Walras um dos seus mais ilustres representantes. Seu objetivo de demonstrar lógico-matematicamente a ordem social do mercado significa que ele guarda a ambição de Smith do mercado como uma teoria da sociedade, ao mesmo tempo que enfrenta questóes epistemológicas em torno da natureza da economia, suas possibilidades demonstrativas e as reduçóes necessárias para tal. Walras, através da releitura que faz de Smith, constrói uma das mais importantes pontes da teoria econômica, inaugurando nesse processo a economia positiva. Uma continuidade constatada por seus herdeiros neowalrasianos contemporâneos, que entendem a solução smithiana como um esboço do modelo canônico walrasiano.

O terceiro momento do pensamento liberal é marcado por uma crítica que parte do interior da ótica do mercado, em que o protagonista principal é o nosso autor, Hayek. Sua crítica atinge aspectos epistemológicos e normativos do modelo walrasiano em três planos: uma crítica à ambição daquele que confecciona o modelo, uma crítica à racionalidade onipotente dos indivíduos e, finalmente, uma crítica à intervenção do planejador ou do governo que pretende corrigir as falhas do mercado. Para Hayek, uma das melhores expressóes da modernidade é a ambiçáo walrasiana demonstrativa do mercado: uma perspectiva que supóe, do ponto de vista filosófico, que o mundo é capaz de ser desvelado pelo uso de um bom método. Ali residiria a ideia equivocada de que os fenômenos econômicos e sociais são passíveis de serem captados por um conhecimento perfeito, no caso, a matemática. O segundo ponto da crítica diz respeito à concepçáo neoclássica ortodoxa do comportamento dos indivíduos que, dotados de racionalidades onipotentes, produzem por suas escolhas racionais uma ordem equilibrada, estável e ótima. Em oposição a 
essa onipotência, Hayek sugere um homem ignorante, seguidor de regras e sabedor de suas limitaçóes frente a um mundo complexo que jamais será totalmente desvelado. Finalmente, sua crítica atinge o racionalismo construtivista do planejador que almeja, a partir de reformas sucessivas, corrigir o mercado - uma contradição em termos para ele, já que toda intervenção, por suposto, é produtora de injustiças e ineficácias.

Hayek - um dos mais importantes teóricos e ideólogos do neoliberalismo - apresenta uma teoria coerente com a sua visão de mundo dos idos de 1940, quando publicou o Caminho da servidão, cujo objetivo era desmontar a possibilidade de leis da história que pudessem conduzir ao socialismo. Ele se apropria dessa noção de curso da história e substitui a utopia do socialismo pela do mercado. Como veremos, suas leis imanentes (as regras necessárias da concorrência capitalista) determinam a ideia de um processo sem sujeito que culminaria na democracia liberal, a face política da vitória da lógica do mercado. Hayek, ao defender o mercado como fim da história e como melhor forma de organização das sociedades contemporâneas, passa sem mediaçóes da teoria para uma defesa apologética do mercado nos tempos atuais. Tempos estes marcados pela descrença desse discurso e pela constatação, em círculos cada vez maiores da academia e da sociedade, da importância visceral do Estado na construção e na manutenção da ordem do mercado capitalista.

\subsection{A ideia central de Hayek: a ordem social espontânea}

O conceito de ordem espontânea tem sua origem, sobretudo, na ordem natural de Adam Smith. Sobre a origem desta noção na história das ideias e a sua contraposição à ideia de uma ordem racional, fabricada, ele afirma:

Foi numa reação contra o racionalismo cartesiano que os moralistas britânicos do séc. XVIII [...] elaboraram uma teoria social que faz dos resultados não previstos das ações individuais seu objeto central, propondo uma teoria geral da ordem espontânea do mercado [...]". A origem da ideia está na filosofia moral britânica do séc. XVIII de Mandeville. Mas o seu desenvolvimento completo só acontece com Montesquieu (que sofre influência de Mandevillle), e em particular de David Hume, Josiah Tucker, Adam Ferguson e Adam Smith, este último afirma que uma mão invisível conduz o homem a servir a um fim que não faz parte de suas intenções [...], aliás, a percepção mais profunda do objeto de toda teoria social. (HAYEK, 2007, p. 162-164).

A ordem espontânea de Hayek, como a de Smith, é o resultado de açôes não intencionais. Ela se contrapóe à ordem racional, uma ordem fruto do 
plano, do desígnio ou da razão. Ela é natural, e esse sentido natural, explica Hayek, está nos antípodas da distinção elaborada pelos gregos, entre natural (não planejado, tosco, irregular) e artificial (planejado, estruturado, regular).

A ordem artificial também nomeada táxis é uma ordem racional construída pelo homem. Para Hayek, não há o que temer das ordens construídas, desde que entendidas no plano das formas de organização concretas, hierarquizadas, e que servem a um propósito comum. Já uma ordem natural é um kosmos, uma ordem que não responde a nenhum desejo, ela é uma ordem endógena que encontra nela mesmo o seu motor. Além disso, esse organismo (não organização) é resultante da evolução e da complexidade e extrapola ao controle da mente humana. Para Hayek, a sociedade é um organismo mais complexo e mais sofisticado que o cérebro humano, e essa ordem complexa regida por regras abstratas permite a gestão de uma quantidade infinita de informaçóes.

O segundo passo dado por Hayek é a passagem e a identificação da ordem espontânea com a ordem do mercado - a melhor expressão para se entender uma rede de intercâmbios catalíticos. A ordem catalítica (que vem da palavra katallatein) significa "trocar" e se preserva, para Hayek, no mito da mão invisível: a tradução exemplar da emergência de uma ordem espontânea. (HAYEK, 1973).

\section{3 ponto de partida filosófico: crítica ao racional construtivismo}

Hayek, em todos os seus mais importantes trabalhos $(1937,1952,1967$, $1973,1988)$, identifica com maestria o cerne dos principais pontos do método cartesiano, retirando daí uma consequência direta desse método: a ação racional é aquela inteiramente conhecida e demonstrável pela razáo e as realizaçóes dos homens são produtos de seu raciocínio. Em suas palavras: "a razão do homem por si só torná-lo-ia capaz de construir a sociedade em novos moldes" (HAYEK, 1973, p. 4).

Hayek inicia a sua crítica à ordem artificial pela filosofia. Ele toma como ponto de partida a crítica filosófica ao racionalismo construtivista, ou a ideia da ordem fabricada, oriunda do desígnio da razão. Sua crítica filosófica dirige-se ao racionalismo de tradiçáo cartesiana, de acordo com o qual o espírito humano através do bom uso de um método rigoroso e universal atinge verdades absolutas e inquestionáveis, sem o recurso de referências empíricas. A razão cartesiana, como sabemos, tem um núcleo central: a dedução lógica de 
premissas apodíticas. Seu coração é matemático e é ele quem dita para Descartes as verdadeiras "Regras para a direção do Espírito". Como consequência direta de seu bom uso, tem-se uma verdade inquestionável e alcançável pela razão. A razão cartesiana se confunde a esse método único, de caráter universal, e traduz um conhecimento perfeito e inteiramente dominado pela inteligência: ta mathema (a matemática). $\mathrm{O}$ mestre da razão moderna enuncia esse método universal em 21 regras, entre elas, as da evidência, da divisão, da síntese e da enumeração. (DESCARTES, 1985 [1623]). A dúvida cartesiana, elemento fundador do cogito, refuta tudo aquilo que é sombrio, nebuloso ou do domínio da opinião e, através de uma dúvida epistemológica, chega às primeiras verdades, axiomáticas, claras e evidentes, garantidoras de uma certeza sintática, atemporal, posto que nelas habitam identidades ideais, sem quaisquer restrições empíricas. (Descartes, 1959, [1641]).

Como derivação desse método racional, temos uma ação que Hayek chama de razão construtivista, ou a ação orientada por uma razão onipotente que tem a ambição de construir ou de corrigir ordens sociais, independentemente da história ou da tradição. Hayek faz uma crítica contundente à noção da sociedade como produto da razáo, pois, segundo ele, a perspectiva racionalista revela desprezo pelo costume, pela tradição e pela história, e carrega consigo a concepção de que a moral, a religião, a linguagem, as leis, as regras e as instituiçóes são frutos do desígnio ou do plano racional.

Da pretensão que ele identificou na razão para criar uma ordem social, Hayek articulou uma segunda crítica: a servidão e o totalitarismo instaurados por essa ordem supostamente fabricada. Segundo o ponto de vista de Hayek, o racionalismo construtivista do processo fascista e do processo de criação da ordem social socialista produziu de suas entranhas uma razão totalitária. A identificação do totalitarismo ao socialismo e o abandono da ênfase na questão fascista mostrou que Hayek estava interessado não no debate entre totalitarismo versus democracia, mas no confronto entre a ordem socialista e a ordem social do mercado, ou seja, no confronto em torno de projetos de sociedade. Nesse contexto afirmou que, contra o totalitarismo ou uma ordem racional fruto do plano, só há um antídoto possível: a ordem liberal do mercado. (HAYEK, 1944) 
Mas Hayek também critica o mercado como uma ordem racional. Para ele, a expressão mais importante dessa teoria do mercado estaria na ambição demonstrativa walrasiana: uma compatibilidade ex-ante de agentes autointeressados e detentores de uma razão onipotente calculadora. Suas escolhas seriam fruto de uma previsão racional, ou de um desígnio intencional que tem como resultado econômico uma ordem equilibrada, estável e ótima.

Identificamos a crítica de Hayek aos neoclássicos como uma variante do racional construtivismo em três planos: em primeiro lugar, no indivíduo autointeressado detentor de uma razão calculadora, cujas escolhas, fruto de uma previsão racional ou de um desígnio intencional, acarretam como resultado econômico uma ordem do mercado racional. Em segundo lugar, no plano teórico-modelizador, que aspira demonstrar matematicamente a superioridade do mercado (o modelo walrasiano da teoria do equilíbrio geral seria exemplar). Finalmente, no político, no planejador, ou ainda no governo, pela sua aspiração de corrigir os efeitos nefastos do mercado. Para Hayek, a mesma concepçáo de onipotência da razáo que dita a racionalidade ilimitada do indivíduo e a arrogância do modelizador dão alimento a uma fragilidade imperdoável dos neoclássicos: a ideia de que é possível não apenas demonstrar o mercado, mas corrigi-lo, reformá-lo, alterando a distribuição natural da renda. Uma interferência que significa negar ao mercado o seu desenvolvimento espontâneo e dar passos, com essas intervençôes, em direção ao socialismo.

Contra essa ordem fabricada, produzida pelo plano e pelo desígnio e que, portanto, supóe um mundo passível de ser captado pelo conhecimento perfeito, Hayek sugere uma ordem que é eminentemente espontânea, o kosmos, fruto de homens seguidores de regras. Não um fruto de regras apriorísticas, inatas ou conhecidas por um espírito humano, mas de regras que seriam transmitidas pela cultura, oriundas da experiência e da tradição. Mas, antes de adentrarmos no mundo hayekiano das regras, vamos explorar o ponto de partida metodológico do seu edifício teórico: o indivíduo, que atua cegamente e que desconhece o resultado coletivo de sua ação, a ordem da sociedade (HAYEK, 1967).

\section{$2.4 \mathrm{O}$ ponto de partida metodológico: o indivíduo}

Hayek honra a tradição anglo-saxônica da modernidade que toma o indivíduo como ponto de partida para a compreensão da lógica dos fenômenos 
coletivos $^{4}$, ao mesmo tempo em que marca a distância do individualismo metodológico utilitarista (de tradição neoclássica), cujo controle de escolhas teleológicas, previsóes racionais e desígnios intencionais é ditado por um cálculo maximizador oriundo de um indivíduo cuja razão é onisciente.

Como contraponto a essa derivação da arrogância da razão cartesiana, que exibe um conhecimento pleno dos fatos e que permite ao indivíduo desvendar a inteligibilidade da sociedade, Hayek parte da radical ignorância dos membros na great society. Nesse mesmo movimento, ele deixa claro que a ignorância, atributo até então desqualificado dos indivíduos, é ironicamente a porta de entrada para se conquistar uma possível liberdade.

Em The Constitution of Liberty afirma que somos livres e ignorantes e, portanto, abertos para o imprevisível e para o não determinado, um horizonte infinito de possibilidades. Em poucas palavras: o homem para ser livre deve exercer essa liberdade na escolha dos fins (HAYEK, 1960).

Tendo como referência antropológica e ontológica uma humanidade imperfeita, Hayek marca sua aversão a qualquer vestígio do homem moderno que, regido por uma onipotente razão, descobre a verdade (HEIDEGGER, 1962). Nas palavras de Hayek (1952):

Apesar de nossa civilização ser o resultado de uma acumulação de conhecimentos individuais não é pela composição de todos esses conhecimentos num cérebro individual, mas sim pela materialização em símbolos, hábitos e instituições, ferramentas e conceitos, isto é, um corpo de conhecimentos que nem ela nem ninguém possui perfeitamente.

Contra a referência filosófica da modernidade que marcou profundamente a concepçáo de razão e da ciência do homem ocidental, ele advoga que nem o espírito nem a razão são anteriores à civilização, mas se desenvolvem simultaneamente a elas. Ignorantes que somos frente a esse mundo complexo, faz-se necessário ter humildade para aceitar a limitação da razão diante de um mundo que jamais será totalmente desvelado. Dele só disporemos de um pequeno,

40 individualismo significa que os fenômenos sociais são determinados pelas ações e pelos comportamentos dos individuos. Entendido também como uma metodologia em oposição ao holismo, em que os fenômenos são totalidades que devem ser apreendidas em nivel macro, e que, mesmo os comportamentos individuais, são determinados pelas totalidades. Para Hayek, a macroeconomia é o lugar do erro científico porque difunde a ilusão de que é possivel estabelecer relações de causa e efeito entre os meios e os agregados. 
incompleto e fragmentado conhecimento. E é tateando, entre erros e acertos, entre conjecturas e novas refutaçóes, que o homem faz uso do conhecimento de que dispóe, ainda que limitado. Através do conhecimento tácito o homem experimenta, aprende e seleciona as melhores regras de comportamento, justas, abstratas e gerais, e que o guiam nesse mundo complexo.

A perspectiva ontológica de Hayek é a de um homem consciente de suas próprias limitaçóes e, portanto, sabedor de sua ignorância, mas também sábio porque as contorna, experimentado e criando novas ferramentas. E isso se verifica num processo de experimentação que para ele é um processo rico de aprendizagem e adequação em que cada indivíduo examina os fatos que conhece e, a partir daí, adapta-se ao mundo tendo em vista seus próprios fins. (HAYEK, 1937;1974). Como apenas uma pequena parte do conhecimento é suscetível de ser verbalizado ou traduzido em regras explícitas, a outra parte aparece por analogia através da experiência da observação.

Com isso Hayek procede a uma crítica a todo e qualquer cientificismo e deixa clara sua inesgotável identificação ao racionalismo crítico popperiano com suas proposiçóes constantemente renovadas de conjecturas, sua humilde correçáo de erros e sua consequente provisoriedade do conhecimento (POPPER, 1972). ${ }^{5}$

\subsection{O elemento central de coalizão da ordem espontânea:}

\section{as regras}

Hayek herda de Smith a noção de ordem social espontânea e a importância das regras para a compreensão da inteligibilidade desta ordem. O conceito de regras é nuclear para o pensamento hayekiano e, embora sob novas

5 A analogia com Popper é fruto da identificação teórica entre os dois e pode ser constatada na ideia de que os homens agindo liuremente num processo aberto de experimentações tateiam, entre erros e acertos, tal qual num processo popperiano do conhecimento movido por conjecturas e refutações. Para Popper, sua razão crítica supera Descartes, Bacon e ainda a tentativa de síntese kantiana nos juízos sintéticos a priori. Consoante com o seu tempo, em que a razão moderna sofre abalos sísmicos, Popper através do seu método dedutivo a priori acena com a provisoriedade do conhecimento, posto que limitado por nossa ignorância latente. Seu compromisso é com proposições constantemente renovadas por novas conjecturas, fruto da correção constante de erros. Tateando entre erros e acertos, o critério que dá substância ao seu método é o da falseabilidade, ou o confronto rigoroso e impiedoso das teorias com a observação e a experiência. Em última instância, trata-se da eliminação das teorias incapazes de resistir aos testes e da substituição por outras conjecturas especulativas mais promissoras (POPPER, 1974[1934]). 
roupagens, provém da experiência tal qual em Smith. O conceito de regras presente tanto nas teorias de Smith quanto nas de Hayek permite que se recupere a contundente natureza filosófica das obras desses dois grandes autores do liberalismo. As regras, por seu papel crucial na explicação da emergência e estabilidade da ordem social do mercado, permitem a Adam Smith marcar sua filiaçáo filosófica empirista face ao racionalismo cartesiano. Hayek, como Smith, complexifica a análise dos processos sociais, levando em conta a intersubjetividade e a sociabilidade, recorrendo para tal, única e exclusivamente, à imponderável e complexa ação dos indivíduos. ${ }^{6}$

Hayek, a partir dessa tomada de posição filosófica, levanta os alicerces de seu edifício teórico: contra uma ação racional determinada por uma verdade alcançável e demonstrável, Hayek sugere um homem seguidor de regras, "consciente de sua ignorância insuperável da maior parte das circunstâncias que determinam os efeitos de nossas açóes." (HAYEK, 1937)

Contra um mundo passível de ser entendido pela razão, Hayek apresenta um mundo evolucionista ditado por regras selecionadas, abstratas e gerais, que guiam os homens num processo de aprendizagem social e coletivo, trazendo como consequência para a sociedade uma progressiva capacidade para resolver problemas. No entanto, essas mesmas regras necessárias que garantem o funcionamento da concorrência deixarão entrever os elementos contraditórios de seu argumento e sua crença ideológica no mercado como única forma possível de organização para as sociedades contemporâneas.

As regras hayekianas emergem num quadro de ignorância e sabedoria, incerteza e seleção, e são elas que dão substractum à ordem espontânea, natural do mercado. Essa ordem catalítica como Hayek a define emana da práxis, da experimentação, e não de um arranjo operado por alguém. Como não é construída, não pode ser reconstruída mentalmente, caracterizando-se por ser uma estrutura transcendental, uma categoria inacessível à razão que expressa uma multiplicidade de fins distintos e incomensuráveis de todos os seus membros individuais (HAYEK,1974).

6 As regularidades de comportamento identificáveis na estrutura analítica de Smith podem ser percebidas pelos existentes entre as regras morais de comportamento do seu Tratado filosófico-moral, a Teoria dos Sentimentos Morais (TSM) e a ação interessada dos sujeitos smithianos na obra, "A Riqueza das Nações" (RN). As regras comportamentais, conceito morfogenético da TSM, são entendidas como coadjuvantes da operação da mão invisivel na Riqueza, como a noção de interesse privado da RN se articula ao conceito de simpatia da TSM (GANEM, 2005). 
Essas regras que reafirmam a ordem social espontânea guiam a sociedade num processo evolutivo oferecendo soluçóes conjunturais para problemas recorrentes. Tem-se aí um modelo de aprendizagem evolucionista definido por um processo de adequaçáo onde os indivíduos são capazes de aprender sistematicamente de seus próprios ensaios e erros.

Finalmente, essas regras selecionadas, produtos da experiência de geraçóes, são abstratas, mas também devem ser gerais, pois não podem atender a fins particulares, e sim respeitar o princípio de aumentar a oportunidade de todos. Nesse ponto, ele frisa uma questão inegociável: não é necessário o consenso com relaçáo aos fins, mas o consenso com relação aos meios capazes de servir a uma grande variedade de propósitos.

\section{Ordem e evolução cultural: do mercado espontâneo como ordem social ao mercado como fim da história}

Hayek na sua teoria da evoluçáo cultural retoma a tradição de Mandeville, Hume e Smith e desenvolve a ideia de uma evoluçáo cultural que é anterior ao conceito biológico de evolução. Hayek identifica no estudo da sociedade a atmosfera do pensamento evolucionista, tradiçáo anterior à contribuição de Darwin. O que as une é a adaptabilidade, seja ela cultural ou biológica/darwiniana, pois ambas refletem a capacidade do homem e do organismo para enfrentar com êxito os problemas, baseadas, exclusivamente, no princípio de ensaio e erro.

O enfoque evolucionista dos filósofos morais escoceses indica que os produtos da civilização são o resultado de um processo de regularidades. Eles não são guiados por uma previsão, mas são frutos do resultado não intencional de ensaios e erros. Um processo que não é resultado da criação consciente das instituiçóes pela razão, mas um processo em que cultura e razão se desenvolvem concomitantemente. É famosa a assertiva de Hayek, de que o homem não adotou novas normas de conduta porque é inteligente: tornou-se inteligente ao se sujeitar a novas normas de conduta (HAYEK, 1973).

A evolução cultural seria na verdade similar a um processo de crescimento do conhecimento, um processo de aprendizagem social e coletivo que teria nas regras suas guias abstratas ${ }^{7}$. Nesse sentido, elas reforçam o jogo catalítico do

7 Hayek redefine o conceito de abstração. "A abstração", diz Hayek, "será a base da atitude do homem para se movimentar num mundo imperfeitamente conhecido por ele, como a maneira de adaptar a sua ignorância na maior parte dos fatos particulares de seu meio" (HAYEK, 1973). 
mercado, o único capaz de produzir riquezas, reafirmando as regras que são aplicáveis a um número desconhecido e indeterminado de casos.

Quanto mais a sociedade se torna complexa, mais é destacado o sentido de espontaneidade das regras, ${ }^{8}$ e mais acertadas as escolhas em torno de regras abstratas e gerais que garantam os meios capazes de servir a uma grande variedade de propósitos. O governo, nesse caso, deve respeitar o fundamento lógico de uma sociedade livre, aceitando que a diferença de oportunidades está relacionada com as eficácias individuais desse processo de descoberta constituído pelo mercado. $\mathrm{O}$ intento de tornar as oportunidades de indivíduos iguais produz injustiças. Para evitar os efeitos nefastos do racionalismo construtivista, Hayek sugere que o Estado garanta os direitos negativos do cidadáo: somente as regras de um governo que favorece o funcionamento catalítico do mercado aumentariam as chances de todos.

Todos estariam constantemente empenhados na solução de problemas e a evolução das estruturas complexas se faria mantendo a ordem, pois os elementos que a compóem obedecem a regularidades e adaptaçóes em última análise. As regularidades de conduta ditadas pela capacidade de seguir normas redundariam na restauração da ordem, caso esta seja perturbada por influências externas. A evolução é vista como o desenvolvimento das potencialidades contidas em germe, um processo pelo qual a teoria, tanto social como biológica, explica a aparição de diversas estruturas complexas (GANEM, 2005).

Evolução e ordem, nesse sentido, são para Hayek conceitos gêmeos que permitem explicar a permanência dessas estruturas complexas, não por meio de uma concepção simples de leis unidirecionais de causa e efeito, mas por uma complexa interação de configuraçóes, chamada por Campbell de "causação descendente".

Aliás, a ordem garante a permanência de estruturas complexas por meio de uma sofisticada interação de seus elementos, e a evoluçáo se expressa num processo de aprendizagem coletivo, transmissão e acumulação de geração em geração de conhecimentos e experiências (HAYEK,1973; CAMPBELL,1987).

8 Hayek diferencia ordem espontânea de organização, essa sim "uma consequência natural da descoberta dos poderes da inteligência humana e resultado do racionalismo construtivista, ela foi a única forma e método inteligente para atingir determinados resultados comuns e previsiveis" (HAYEK,1973). 
Essa visão em que todos os organismos estão constantemente empenhados na solução de problemas é definido por Hayek como algo natural, e isso não implica uma sucessão de etapas caminhando para um fim determinado. É divergindo desse ponto que Hayek constrói sua crítica ao racionalismo construtivista de herança marxista: uma razão que transforma a sociedade numa máquina racional, uma razão que é capaz de digerir a sua própria complexidade e que constrói pela deliberação de seus sujeitos sociais um devir socialista (HAYEK, 1988,[1973]).

Razão e cultura, para ele, se desenvolvem concomitantemente. Criticando o que chama de discurso profético de Marx, ele dirá: "A sociedade não deve ser dirigida para um fim escatológico" (HAYEK, 1988 [1973]). Contra isso ele advoga uma teoria da evolução cultural que proporciona uma versão de como funciona o processo sem tentar explicar através da razão seus resultados ou predizer seu curso. Entretanto, é possível observar que o racionalismo construtivista que o autor tanto critica nos seus opositores está contraditoriamente presente no seu argumento, gerando dogmatismo e um apologético conservadorismo na defesa incondicional do mercado como presente e devir das sociedades.

Podemos observar que são as mesmas regras de funcionamento da ordem catalítica do mercado que deixam a nu as contradiçóes do seu argumento teórico quando este é jogado para o plano da história. Nesse plano de compreensão, teoria, retórica e ideologia conservadora acabam por se irmanar na sua ardorosa defesa ultraliberal da superioridade do mercado como única forma possível de organização das sociedades contemporâneas. É o que veremos a seguir.

A função da concorrência para Hayek é mostrar quais planos estão errados e evidenciar que a distribuição resultante, ainda que não seja materialmente a mais justa, provém de um processo que aumenta o número de ocasióes propícias ao sucesso de todos. O legislador (o governo), nesse caso, tem o dever de garantir esta ampliação da chance de todos. Na verdade, ele deve velar para que se garantam as regras comprometidas com o aumento da probabilidade de sucesso de pessoas desconhecidas, cujas oportunidades dependerão, sobretudo, de seu conhecimento e habilidades individuais. Essas regras garantidoras da concorrência são as regras exitosas per se. Como não é necessário haver concordância de seus membros quanto aos fins, a natureza da atividade econômica é conciliar os fins competitivos. O jogo da catalaxia, 
como Hayek o define, é o jogo puro da riqueza, e a política só pode ter como objetivo aumentar a probabilidade de qualquer membro desconhecido na realização de seus propósitos igualmente desconhecidos (HAYEK, 1973).

Victor Vanberg aponta nesse ponto uma contradição interessante: se não podemos dizer nada acerca do que esperamos do que seja exitoso, não podemos discutir se o que sobrevive é o desejável. (VANBERG,1999, p. 209). Essa ambiguidade se faz presente quando Hayek fala de mercado, pois, indiretamente, está tratando de leis jurídicas adequadas, que por suposto, servem aos interesses de grupos organizados ou não. Não é fácil sustentar, como faz Hayek, que as ordens espontâneas tenham sempre efeitos benéficos, quaisquer que sejam os termos da concorrência. E também é complicado afirmar (sob pena de adentrarmos no terreno do dogmatismo) que haja um processo natural de evolução cultural, sem restriçôes. ${ }^{9} \mathrm{Na}$ verdade, Hayek desliza por esses pontos controversos e admite que "existe uma construção constitucional deliberada e um desígnio institucional que tem o papel de criar as condiçóes para que a sociedade possa evoluir para melhor" (Hayek, 1973).

A sociedade não deve ser dirigida para um fim específico, escatológico, como propala Marx, diria Hayek. Sua evolução deve ser guiada pelo que é imprescindível para assegurar as propriedades de funcionamento desejáveis à manutençáo do sistema competitivo. Ou em outras palavras, guia-se o processo competitivo através de um marco adequado de regras. Ora, estamos falando de regras necessárias para que o jogo catalítico espontâneo funcione. Não nos parece uma contradição? Ainda que Hayek admita certo construtivismo na experimentação deliberada em assuntos institucionais e se coloque radicalmente contra o poder monopolista exclusivo, seu argumento não escapa da crítica que faz ao ultrarracionalismo.

Embora não saibamos de antemão quais as regras que de fato farão o mercado funcionar, serão sempre elas as exitosas, as escolhidas, posto que mercado para Hayek é sinônimo de método. Uma tautologia ou um método tão indispensável como a matemática o foi para Descartes. Um método que

9 Ver, a propósito, algumas críticas sobre efeitos não necessariamente benéficos da concorrência e processo de evolução cultural com restrições e ambiguidades em (BIANCHI, I994); (BARRY, I994); (JOSSA, 1999); (HODGSON, 1994); (PLANT, 1994); (ULMANN-MARGLIT, 1997); (SAMUELS, 1999); (WITT, 1999); (RADNITZKY, I999); (SHEARMUR, 1999); (VAUGHAN, 1999). 
não é derivado da lógica matemática, mas da experiência, da práxis. Mas um método, em última instância, sem o qual não se é possível pensar a sociedade. Poderíamos dizer que a inquestionável necessidade desse método ou do mercado o desloca para o plano intocável, ideal, em última análise. Tão apodítico, racional e certo, como as regras aprioristas, cartesianas, que ele tanto critica.

Nesse ponto é interessante a crítica que o filósofo Luc Ferry faz, ao afirmar que o hiper-racionalismo de Hayek é como o de Hegel, porque, em última análise, tudo se desenvolve racionalmente e que todas as iniciativas, mesmo as mais irracionais, participam da autorrealização de uma razão: a do mercado. ${ }^{10}$ Tal como Ferry, é possível supor que Hayek cai na armadilha da razão e termina por reeditar, como Laplace e Hegel, o mito de descobrir leis imutáveis e eternas para a história. Aliás, é esse mito da mão invisível como um processo impessoal e inexorável que tem sustentado a apologia e a retórica dos ultraliberais na defesa do mercado como a única forma de organização para as sociedades contemporâneas. Em última análise, a mão invisível é o meio e o fim da Great Society: a própria inteligibilidade das sociedades complexas. Hayek extrapola os limites do econômico ou de qualquer disciplina stricto sensu para se colocar no plano da filosofia social e da teoria da história. ${ }^{11}$ (GANEM, 2005; 2009).

\section{À guisa de conclusão: o mercado de Hayek como grande narrativa moderna}

Hayek reedita o mito da mão invisível no processo de evolução cultural, colocou-se no plano de uma teoria da história. Sua perspectiva de fim da história (numa versão teórica muito mais sofisticada que a de Fukuyama,

10 Citando Luc Ferry: "o hiperliberalismo de Hayek é um hiper-racionalismo porque ele pressupõe como Hegel que na história tudo se desenvolve racionalmente e que mesmo as iniciativas aparentemente mais irracionais participam da autorrealização de uma razão: a do mercado [...]. À força de preservar os direitos e a liberdade dos efeitos nefastos do intervencionismo, o liberalismo hayekiano confia tudo à história ou ao autodesenvolvimento do mercado" (FERRY, 1984).

II A essa altura, algumas questões ficam pendentes na sua teoria. Atenho-me a duas que considero pertinentes para o objetivo proposto. São elas: I) como justificar que as regras da concorrência serão sempre as melhores, as exitosas, as escolhidas enfim, sem sair do campo da espontaneidade e da não previsibilidade do curso da história, seu território preferido, para entrar no campo de uma necessidade racional? 2) como criticar o racionalismo de Marx em que ele supostamente buscaria como um mito racional descobrir leis imutáveis e eternas para a história se ele próprio reedita o mito da mão invisivel e entende o mercado como passado. presente e devir para as sociedades contemporâneas? 
1992 $)^{12}$ traduz a ideia da eliminação de quaisquer outras alternativas de organização social frente ao mercado. O ponto crucial que o diferencia dos discursos do mercado puramente apologéticos: a ordem que emerge no processo de evolução cultural é uma ordem escolhida pelos sujeitos sociais. Nisso reside a diferença da concepção hayekiana das demais teorias que pregam o mercado como fim da história e é sem dúvida o que a torna mais pujante e instigante: a inexorabilidade do mercado se alimenta de regras escolhidas por indivíduos de forma natural e espontânea. Os sujeitos sociais hayekianos náo se definem pela anulação, pelo esquecimento da política, por sua alienação ou ainda, pela "dissipação em meio à rotina trivial de fazer compras e votar" nos termos de Jameson. Eles são ativos e elegem em meio a sua ignorância as regras que garantem a ordem e a manutenção do mercado.

Embora o traço definidor da pós-modernidade seja a perda de credibilidade das metas narrativas ou o eclipse das narrativas grandiosas da modernidade (ANDERSON,1992; JAMESON, 1998; DUFOUR, 2005), Hayek se impóe no quadro do discurso cético pós-moderno recuperando o domínio de uma poderosa narrativa: a de uma evoluçáo cultural que garante inexoravelmente a vitória global do mercado. Para compreender criticamente como os valores da concorrência, da ética individualista do capitalismo se introjetam nos indivíduos e os fazem legitimar as regras necessárias à reprodução (via valores) do sistema, ou ainda, compreender em termos mais sofisticados a passagem da teoria à apologia do mercado, não dá para passar ao largo da teoria do mercado de Hayek.

\section{Referências}

ANDERSON, P. O fim da história: de Hegel a Fukuyama. Rio de Janeiro: Jorge Zahar, 1992.

BARRY, N. The road to freedom: Hayek's social and economic philosophy. In: Birner, J.; Van Zijp, R. (eds.). Hayek, co-ordination and evolution: his legacy in philosophy, politics, economics and the history of ideas. New York; London: Routledge 1994.

12 A teoria do fim da história de Fukuyama afirma que após a destruição do socialismo e do fascismo, o capitalismo e a democracia burguesa se constituem no coroamento da história da humanidade ou, em outras palauras, o fim da história (FUKUYAMA, 1992). É interessante posto que contraditório, como Fukuyama, um dos autores mais entusiastas da ideia do mercado capitalista e da democracia liberal como fim da história (uma leitura racionalista da história), em artigo recente (FUKUYAMA, 20II), faz uma crítica ao ultrarracionalismo hayekiano, crítica esta elaborada primeiramente pelo filósofo francês Luc Ferry, quase duas décadas antes (FERRY, 1984). 
BIANCHI, M. Hayek's Spontaneous order: the "correct" versus the "corrigible" society. In: Birner, J.; Van Zijp, R. (eds.). Hayek, co-ordination and evolution: his legacy in philosophy, politics, economics and the history of ideas. New York; London: Routledge 1994.

BUTLER, E. A contribuição de Hayek às idéias políticas e econômicas de nosso tempo. Rio de Janeiro: Instituto Liberal, 1987.

CAMPBELL, D.T. The two distinct routes beyond kin selection to ultra sociality. In: BRIDGEMAN. (Org). The Nature of Prosocial Development. New York: Academic Press,1987.

DESCARTES, R. [1641] Discours de la méthode. Paris: La Pléiade,1959.

[1623] Regras para a direção do Espírito. Lisboa: Edições 70, 1985.

DOLSTATER, G. Le Libéralisme de Hayek. Paris: La Découverte, 2001.

DOLSTATER,G.; ETHIER, D. Friedrich Hayek: philosophie, économie et politique. Paris: Ed. Économica, 1989.

DUFOUR, R. D. A arte de reduzir as cabeças: sobre a nova servidão na sociedade ultraliberal. Rio de Janeiro: Companhia de Freud, 2005.

FERRY, L. Philosophie politique. v. II. Paris: PUF, 1984.

FUKUYAMA, F. O fim da história e o último homem. Rio de Janeiro: Rocco, 1992.

Friedrich Hayek, Big-government Skeptic. Disponível em: <www.n.ytimes.com>. Acesso em: 08 maio 2011.

GANEM, A. Regras e Ordem em Smith e em Hayek. Endoxa, Madrid, Series Filosóficas, n. 21, 2005.

. Crítica à leitura hayekiana da história: a perspectiva da ação política de Hannah Arendt. Nova Economia, Belo Horizonte, v. 19, n. 2, p. 267-284, 2009.

Karl Popper versus Theodor Adorno: liçôes de um confronto histórico. Revista de Economia Política, São Paulo, vol.32, n.1, Jan./Mar 2012a.

O Mercado como ordem social em Adam Smith, Walras e Hayek. Economia e Sociedade, Campinas, vol. 21, n. 1 (44), p. 143-164, Abr. 2012b.

HAYEK, F. A. Prices and Production London: Routledge and Sons, 1931.

. Monetary Theory and the Trade Cycles. London: Jonathan Cape, 1933.

The Pure Theory of Capital. London: Routledge and Kegan Paul, 1941. 
. Individualism and Economic Order. Chicago: University of Chicago Press, 1937.

. Economics and Knowledge. In: Economica, v. 4, 1937b, p. 33-54.

. [1944] La Route de la Servitude. Paris: PUF, Quadrige, 1985.

. The Counter-Revolution of Science. Glencoe: Free Press, 1952a.

. The Sensory Order. Chicago: University of Chicago Press, 1952b.

. The Constitution of Liberty. Chicago: University of Chicago Press, 1960.

. Studies in Philosophy, Politics and Economics. Chicago: University of Chicago Press, 1967.

. Law, Legislation and Liberty (tomos I, II e III). London: Routledge and Kegan Paul, 1973.

. New Studies in Philosophy, Politics, Economics and the History of Ideas, Chicago: University of Chicago Press, 1978.

. [1960] Os Fundamentos da Liberdade. Brasília: Editora Universidade de Brasília, 1983.

. [1973] Direito, Legislação e Liberdade. v. I, II e III. São Paulo: Editora Visão 1985.

. The Fatal Conceit: the Errors of the Socialism. Bartley, Routledge, 1988.

. The Collected Works of F.A Hayek. v.1. Routledge and Francis Group, 1991.

HEIDEGGER, M. L'époque des conceptions du monde. In Chemins qui ne mènent nulle part. Paris: Gallimard, 1962.

HODGSON, G. Hayek, evolution, and spontaneous order. In: Mirowiski, P. (Org). Natural Images in Economic Thought. Cambridge University Press, 1994.

JAMESON, F. A Virada Cultural: reflexôes sobre o pós-moderno. Rio de Janeiro: Civilização Brasileira, 1998.

JOSSA, B. Ordine Spontaneo e liberalismo secondo Hayek. Studi Economici, Napoli, n. 49, 1994.

NEMO, P. La societé de droit selon F. A. Hayek. Libre Echange. Paris: PUF, 1988.

PLANT, R. Hayek on social justice. In: Birner, J.; Van Zijp, R. (eds.). Hayek, co-ordination and evolution: his legacy in philosophy, politics, economics and the history of ideas. New York; London: Routledge 1994.

RADNITZKY, G. Hayek's Political Philosophy: a Critical Assessment. Journal des Économistes et des Études Humaines, v. 9, n 2, p. 398-433, 1999. 
SAMUELS, W. Hayek from the perspective of the Institucionalist Historian of Economic Thought: an Interpretative Essay. Journal des Économistes et des Études Humaines, v. 9, 1999.

SHEARMUR, J. Hayek and the Future of Political Philosophy. In: Journal des Economistes et des Etudes Humaines. v. 9, n. 2, 1999, p. 437-453.

VANBERG, V. Racionalidad y Regras. Barcelona: Gedisa Editorial, 1999.

VAUGHAN, K. Hayek's Theory of the Market Order as an instance of the Theory of Complex, adaptative systems. Journal des Économistes et des Études Humaines, v. 9, 1999.

ULLMANN-MARGALIT, E. The invisible hand and the cunning of Reason. Social Research, v.64, n. 62, 1997.

WITT, U. The theory of Societal Evolution. In: Birner, J.; Van Zijp, R. (eds.). Hayek, co-ordination and evolution: his legacy in philosophy, politics, economics and the history of ideas. New York; London: Routledge 1994.

Recebido em: 11.09.2011

Aprovado em: 13.02.2012

\section{Hayek: from the theory of spontaneous order market to the market as the end of history}

\section{Abstract}

The text aims to demonstrate the centrality of the of market's spontaneous order concept in Hayek, examining it from multiple aspects, ranging from the structuring concept of his theoretical construction to the idea that the social order derived from it is conceived as the best social organization model for contemporary societies. The paper aims to underscore the relevance of Hayek's work highlighting, this was one of the greatest expressions of ultra-liberalism, underscore the society's worldview, his philosophical critique of rational constructivism, as well as his conception of an ignorant person facing the complexity of the world. The paper's second movement deals with the contradictions of the hayekian theory of cultural evolution in which the market is understood as past, present and future of contemporary societies. This last point where the market is understood as the end of history allows us to identify the ultra rationalism perspective of Hayek and indicate how his theory supplies an apologetic defense of market as the only form of organization for contemporary societies.

Keywords: Hayek. Spontaneous order. Cultural evolution. End of history. 